\title{
El desarrollo del capitalismo a escala mundial en la filosofía de la historia de Marx: difusionismo y tradición crítica
}

\author{
The development of capitalism on a world scale in the philosophy of history \\ of Marx: diffusionism and critical tradition
}

\author{
Mariano Treacy*
}

Resumen: En este trabajo intentaremos plantear la hipótesis de que la crisis del marxismo y las dificultades del socialismo real (particularmente el caso soviético) se vincularon en algún punto con la dimensión filosófica y los elementos sobre filosofía de la historia en la obra de Marx y Engels. A partir de las filosofías de la historia presentes en sus escritos, se han consolidado diferentes tradiciones dentro del marxismo, de las que nos interesará estudiar en particular la tradición difusionista, que proporcionará el soporte teórico-filosófico del estalinismo a través del DIAMAT. El objetivo del trabajo consistirá por lo tanto en identificar en la obra de Marx y Engels aquellos elementos que dieron lugar a la corriente difusionista y a la interpretación del DIAMAT como filosofía de la historia oficial del movimiento comunista internacional. Luego, rescataremos la tradición más humanista del pensamiento de Marx para reflexionar sobre la potencialidad del pensamiento crítico en la actualidad.

Palabras Clave: marxismo, socialismo, determinismo, reduccionismo economicista

\begin{abstract}
In this paper we will try to propose the hypothesis that the crisis of Marxism and the difficulties of real socialism (particularly the Soviet case) were linked at some point with the philosophical dimension and elements about the philosophy of history in the work of Marx and Engels. From the philosophies of history present in his writings, different traditions have been consolidated within Marxism, of which we shall be interested in studying in particular the "diffusionist" tradition, which will provide the theoretical-philosophical support of Stalinism through DIAMAT. The aim of the work will therefore be to identify in the work of Marx and Engels those elements that gave rise to the diffusionist current and to the interpretation of DIAMAT as the official philosophy of the history of the international communist movement. Then we will rescue the most humanist tradition of Marx's thought to reflect the potentiality of critical thinking today.
\end{abstract}

Key Words: marxism, socialism, determinism, reductionism in economics

Recibido: 30 noviembre 2016

Aceptado: 22 febrero 2017 


\section{Introducción}

El marxismo es una teoría capaz de pensar la historia como progreso y como catástrofe simultáneamente

Michael Löwy

La exclamación "Por fin ha estallado la crisis del marxismo!" hecha por Althusser en 1978 fue sintomática de las dificultades por las que estaban transitando en aquel entonces el campo socialista y los Partidos Comunistas en general y la Unión de las Repúblicas Socialistas Soviéticas (URSS) y el Partido Comunista de la Unión Soviética (PCUS) en particular.

Luego de la muerte de Joseph Stalin en 1953 y principalmente tras la presentación del "Informe Secreto" por parte de Nikita Khrushchev en el XX Congreso del PCUS en 1956, comenzó un proceso de “desestalinización” del modelo soviético ${ }^{1}$ que iluminó aquellas dificultades, lagunas y puntos oscuros con los que se había enfrentado la construcción del socialismo en la URSS, que derivarían en la "crisis del marxismo" proclamada por Althusser.

Hasta ese momento, el stalinismo se había logrado imponer como la fracción líder dentro del PCUS y había construido una hegemonía al interior del movimiento comunista internacional que quedó canonizada en la III Internacional (mundialmente conocida como COMINTERN (1919-1943) y en los conocidos manuales soviéticos de economía.

Desde la perspectiva de Althusser (1978a) compartida por otros intelectuales marxistas críticos del Comintern, la hegemonía stalinista convirtió a la teoría marxista en una "doctrina escolástica", mutilando su carácter crítico, contradictorio y dialéctico mediante el abuso del aparato político e ideológico bajo su control.

A fines de los '70 los países del campo socialista y el movimiento comunista internacional se encontraban en crisis. La magnitud de la crisis del movimiento comunista se podía verificar en el hecho de la ruptura de la alianza estratégica entre China y la URSS y también entre los Partidos Comunistas de Occidente y la URSS (Althusser, 1977). La crisis del campo socialista tuvo un impacto determinante sobre el marxismo y la hegemonía stalinista, que había prevalecido hasta el momento.

\footnotetext{
${ }^{1}$ En una entrevista realizada por Perry Anderson, Lucio Coletti, referente del PC Italiano, afirmaría: “(...) la muerte de Stalin en 1953 tuvo sobre mí un efecto diametralmente opuesto al que tuvo sobre la mayor parte de los intelectuales comunistas o procomunistas. Ellos lo sintieron como un desastre, la desaparición de una especie de divinidad, mientras que para mí fue una emancipación (...)yo experimenté las denuncias de Stalin hechas por Jruschov como una auténtica liberación" (Anderson, 1975: 63)

${ }^{2}$ Vinculado a la hegemonía global del stalinismo, con relación con la crisis del marxismo Althusser plantea que Partido Comunista Francés (PCF) "se subió al carro del estalinismo y entró, con sus propias aportaciones, en la era de las vulgaridades oficiales, que convertían a la teoría marxista, dogma de Estado Internacional, en un positivismo evolucionista, y al materialismo dialéctico en 'la ciencia de las ciencias'" (Althusser, 1978b: 39).
} 
Los principales aspectos de la crisis del marxismo tocan puntos centrales del pensamiento de Marx como la teoría clásica de las clases sociales, la función del desarrollo del capitalismo en el progreso histórico, la del advenimiento del comunismo, las dificultades de la transición socialista, el principio de dictadura del proletariado y el problema de la organización, entre muchos otros.

La deriva stalinista del pensamiento marxista y la deriva soviética del ideal socialista configuran ciertamente casos particulares dentro del infinito abanico de derivas "posibles" del marxismo y el socialismo. Será objeto de este trabajo vincular la crisis del marxismo y las dificultades del socialismo real (particularmente el caso soviético) con la dimensión filosófica y los elementos sobre filosofía de la historia en la obra de Marx y Engels. Para ello, se planteará la hipótesis de que en la obra de Marx y Engels se pueden hallar filosofías de la historia incompatibles entre sí, y que esta incompatibilidad ha sido la fuente sobre la cual se han consolidado diferentes tradiciones dentro del marxismo. En particular, nos interesará estudiar la tradición "difusionista" ya que, como se intentará demostrar a lo largo del trabajo, será la que proporcionará el soporte teórico-filosófico del estalinismo mediante la herramienta del DIAMAT (Dialéctica Materialista marxistaleninista).

El objetivo del trabajo consistirá por lo tanto en identificar en la obra de Marx y Engels algunos elementos que dieron lugar a la corriente difusionista y a la interpretación del DIAMAT como filosofía de la historia oficial del movimiento comunista internacional. En otras palabras, se pretenderá indagar cuánto de la crisis del marxismo responde en realidad a elementos presentes en la obra de Marx y Engels que, apropiados por la ortodoxia comunista para ser funcionales a sus estrategias de poder, terminaron por configurar algunos de los elementos más oscuros de las experiencias del socialismo real.

La discusión que nos presenta la interpretación del marxismo como filosofía de la historia nos resulta central para comprender la crisis que experimentó el marxismo entre 1965 y 1990 (Balibar, 2015) ya que nos permite preguntarnos acerca de la inevitabilidad, la universalidad y la necesidad del desarrollo histórico y problematizar la forma concreta que adoptó en las experiencias del socialismo real. En pleno contexto de crisis, tras derrumbarse la expectativa de la superación "científica" y "racional" por parte del socialismo como proyecto humanitario civilizatorio y del marxismo-leninismo como ideología oficial, como método y como programa, las verdades históricas que se habían derivado de aquella filosofía de la historia deben seguir siendo reconsideradas.

En la actualidad, 25 años después del derrumbe de la bipolaridad global que imponía la existencia de los socialismos reales, el campo problemático es radicalmente distinto. El capitalismo experimenta crisis cíclicas y sigue sin resolver los problemas vitales de la mayoría de la población mundial. Se amplía la brecha que mide la distribución de la riqueza y del ingreso tanto entre los ricos y los pobres como entre los países más ricos y los países más pobres y se destruye el sustrato ambiental sobre el cual se sostiene el crecimiento económico. Adicionalmente, persisten las brechas de género y los conflictos inter-religiosos. Por último, la democracia y la participación política de las mayorías en los asuntos públicos siguen siendo asuntos irresueltos. 
El modelo civilizatorio que propone el capitalismo es tanto injusto como insostenible. La crítica de la economía política y todo el herramental provisto por Marx vuelven por lo tanto a ser un aporte insustituible para la organización política y la proyección de una forma de organización superadora. En este trabajo, por lo tanto, intentaremos respondernos la pregunta de si es posible derivar una "otra" filosofía de la historia del pensamiento de Marx y si el marxismo puede ser otra cosa que una filosofía del progreso ¿capitalista? unilineal.

En la primera parte presentaremos brevemente el campo problemático donde se inscribe este trabajo. Luego rastrearemos el origen de estas tradiciones mediante el repaso de algunos fragmentos de los textos originales de Marx y Engels para adentrarnos en una descripción de la filosofía de la historia hegemónica en el "socialismo realmente existente" de la URSS. Más adelante veremos la tradición humanista y dialéctica de Marx, para finalmente evaluar las implicancias contemporáneas de este debate y exponer unas breves reflexiones finales.

\section{El marxismo como una filosofía de la historia y el embrión de la interpretación difusionista}

\section{(...) con esta formación social se cierra, por lo tanto, la prehistoria de la sociedad humana}

Karl Marx

Distintas lecturas de Marx han conducido a diferentes conceptualizaciones del desarrollo del capitalismo y de las contradicciones que engendra el proceso de acumulación del capital. A lo largo del Siglo XX, no fueron pocas las voces dentro del campo del marxismo que afirmaban que solo una vez consolidado el capitalismo sería posible "superar" la prehistoria de la humanidad para finalmente dar inicio a la historia mediante la construcción de la sociedad comunista. El mismo Marx, en el Prólogo a la Contribución a la Crítica de la Economía Política, afirmó lo siguiente:

A grandes rasgos, podemos designar como otras tantas épocas de progreso en la formación económica de la sociedad el modo de producción asiático, el antiguo, el feudal y el moderno burgués. Las relaciones burguesas de producción son la última forma antagónica del proceso social de producción; antagónica, no en el sentido de un antagonismo individual, sino de un antagonismo que proviene de las condiciones sociales de vida de los individuos. Pero las fuerzas productivas que se desarrollan en la sociedad burguesa brindan, al mismo tiempo, las condiciones materiales para la solución de este antagonismo. Con esta formación social se cierra, por lo tanto, la prehistoria de la sociedad humana (Marx, 1859)

El pensamiento de Marx fue muchas veces interpretado en el sentido de una "reducción de las principales formaciones socioeconómicas a una única escalera por la cual todas las sociedades humanas ascienden escalón a escalón pero a diferentes velocidades por lo que todas, eventualmente, llegan hasta la cima" (Tarcus, 2008). En palabras del propio 
Marx, "los países industrialmente más desarrollados no hacen más que poner delante de los países menos progresivos el espejo de su propio porvenir" (Marx, 2000).

Kevin Anderson (2010) sostiene que el pensamiento de Marx pasó de concebir una lectura en la que el atraso sería "absorbido" por la modernidad capitalista a una en la que el desenvolvimiento histórico conllevaría cursos abiertos y multilineales, donde no habría una direccionalidad histórica preestablecida. Para Kohan (2003) se trató de un cambio de paradigma, donde Marx abandonó el reduccionismo productivista y lo reemplazó por un enfoque multilineal donde la lucha de clases tenía un rol protagónico por cumplir en el proceso de cambio social. Pérez (2007), en un estudio de la obra de Walter Benjamin, también encuentra "dos tendencias" en el pensamiento marxista, derivadas de una tensión entre el cientificismo naturalista y el materialismo dialéctico crítico como método para el estudio de las ciencias sociales.

De las dos tendencias, en este trabajo estudiaremos principalemente aquella que se encuentra más influenciada por el iluminismo, el cientificismo naturalista y el positivismo. La corriente "difusionista", como será caracterizada (De Paula, 2014), interpretó el desarrollo de la acumulación del capital como un proceso de "difusión" en el que la modernización derivada de la expansión del capitalismo promovería el progreso general mediante la incorporación de técnicas novedosas y la demolición de formas previas, potenciando el desarrollo de las fuerzas productivas. Así, el proceso de desarrollo universal se daría de forma unilineal, lo que indicaría que todas las formaciones sociales atravesarían los mismos estadios rumbo al progreso ${ }^{3}$.

El difusionismo en el marxismo compartirá con la sociología funcionalista y el liberalismo económico ${ }^{4}$, tres pilares fundamentales sobre los cuales erige su cosmovisión filosófica (Nimni, 1989):

i. Una teoría de la evolución (una visión de la historia como una serie progresiva de cambios mediante etapas universales y jerárquicamente definidas);

ii. Una teoría determinista que analiza mediante un reduccionismo económico todos los cambios sociales como el resultado automático del desarrollo de las fuerzas productivas; iii. Una visión del mundo eurocéntrica, que sería la consecuencia necesaria e inevitable de la teoría de la evolución y el determinismo económico.

\footnotetext{
3 Con respecto a la visión marxista del progreso, Wallerstein señala que "No debemos olvidar que Liberalismo y Marxismo son herederos del pensamiento iluminista y su profunda fe en el progreso inevitable“ (Wallerstein, 1985 - tomado de De Paula, 2014: 16)

${ }^{4}$ Alain Lipietz escribe en los años '80 un breve artículo para la revista New Left Review (Marzo-Abril 1982) denominado provocativamente "Marx or Rostow". En este artículo compara el etapismo en la obra de Marx con el etapismo en la obra del "padre" de las teorías económicas etapistas del desarrollo, Walt Whitman Rostow, cuya obra principal fue "Las etapas del crecimiento económico: un manifiesto no comunista" (1952). En esta obra, de matriz funcionalista y liberal, Rostow señala cinco etapas de desarrollo histórico: sociedad tradicional, etapa de transición, despegue económico, camino a la madurez y consumo a gran escala. La sociedad de consumo actual sería, bajo su perspectiva, la culminación del proceso de desarrollo histórico de la humanidad.
} 
Para los marxistas "difusionistas", el capitalismo es una etapa necesaria del desarrollo de la historia universal, en la cual el desarrollo de las fuerzas productivas permite acceder a una etapa superior. Esta etapa superior del capitalismo, la modernidad, completaría las condiciones necesarias (aunque no suficientes) para promover el establecimiento de un modo de producción comunista. El balance que se hace desde el difusionismo de la expansión del capitalismo sobre otros modos de producción contiene una tensión entre la admiración de la "misión civilizatoria" del capitalismo y la condena moral que se realiza sobre su avance, ya que se admite que en su desenvolvimiento es sumamente destructivo pero que a pesar de esto su implantación es necesaria para la creación de la estructura para el desarrollo, que aportaría las condiciones “objetivas" para su superación. En sus versiones más extremas (Warren, 1980) el difusionismo llegaría a elaborar visiones apologéticas del imperialismo y de la expansión del capitalismo occidental en tanto vector del progreso 5 .

A diferencia de las filosofías "burguesas" del progreso (cuyo sujeto histórico es en todo caso el individuo), el difusionismo encontrará en el proletariado industrial el sujeto de cambio y en el comunismo la superación de la prehistoria y el comienzo de la historia. Los "pecados capitales" de esta tendencia serán, para Graziano (1994) la realización de un reduccionismo fisicalista ${ }^{6}$ y la portación de una filosofía teleológica de la historia ${ }^{7}$ y una visión evolucionista del progreso social. Por lo tanto, "difusionista" será aquella corriente de pensamiento dentro del marxismo cuya filosofía de la historia ${ }^{8}$ se construya sobre la base del evolucionismo histórico, el determinismo económico y una cosmovisión eurocéntrica 9 .

5 En "El Manifiesto...", Marx y Engels plantean algunas afirmaciones que podrían ser leídas como "apologéticas" de la tarea histórica del capitalismo destruyendo el orden feudal y las formaciones sociales "arcaicas". En la misma dirección, Engels apoyaría la anexión la California "mexicana" por parte de los Estados Unidos ya que "los activos Yankees serían mejores que los indolentes Mexicanos" para asegurar el crecimiento económico de la región. En el extremo, Engels incluso llegaría a justificar la conquista de Argelia por parte del Imperio Francés como "un evento feliz para el progreso de la civilización" (Lowy y Traverso, 1990).

${ }^{6}$ Para Graziano (1994) el reduccionismo fisicalista implica una reducción de la explicación de los hechos sociales a leyes de la física newtoniana (mecánica).

${ }^{7}$ El sistema filosófico del Hegel de la Fenomenología del Espíritu y la Ciencia de la Lógica plantea un sentido

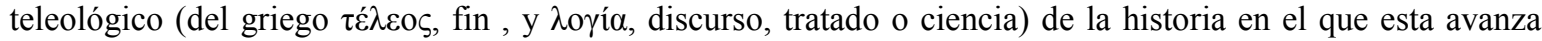
guiada por el desarrollo de la razón hacia un estado de verdad absoluta. El motor de la historia es el desenvolvimiento del Espíritu y la conciencia en su autoconocimiento. Para una investigación más acabada de la filosofía hegeliana se recomienda el texto de Rubén Dri “Los modos del saber y su periodización”, Buenos Aires, Biblos, 2005.

${ }^{8}$ Más adelante se hará referencia a las características de esta filosofía: el materialismo histórico (HISMAT) y el materialismo dialéctico (DIAMAT).

${ }^{9}$ La discusión sobre evolucionismo, determinismo y eurocentrismo en la obra de Marx y Engels y su correlato en la conceptualización sobre el rol del desarrollo de las fuerzas productivas, la acumulación del capital y el cambio histórico nos permitirá abordar la aparición de la "Cuestión Nacional" y el problema del Subdesarrollo en autores posteriores, cuyas interpretaciones tendrán como punto de partida estos debates. Los teóricos marxistas del imperialismo (Lenin, 1916; Luxemburgo, 1917; Trotsky, 1935 y 1957); Neomarxistas (Mandel, 1970; Amin, 2001; Harvey, 2007; Callinicos, 2001) y dependentistas (Marini, 2008; Dos Santos, 1971; Gunder Frank, 1970; Cardoso y Faletto, 1969) postulan una visión en la que el desarrollo del capitalismo es inherentemente desigual, y establecen un esquema de articulación dialéctica entre el progreso económico y el retraso, o, en otras palabras, entre el desarrollo y el subdesarrollo. 
El evolucionismo en la historia implica reducir la complejidad de las transiciones de todos los sistemas económicos hacia la modernidad capitalista a una misma sucesión universal de etapas históricas. La filosofía de la historia teleológica elimina la distinción entre las diferentes formaciones sociales y establece una transición mecánica y determinista entre los distintos sistemas económicos, que culmina en el establecimiento de un orden superior.

El reduccionismo económico fatalista hace referencia a la relación que existe entre la base económica ${ }^{10}$ y el cambio social ${ }^{11}$. En particular, postula que el desarrollo de las fuerzas productivas ${ }^{12}$ es el motor de la historia, ya que hace que entren en contradicción las relaciones sociales de producción. Por lo tanto del progreso técnico se derivan progresos sociales y culturales y grados mayores de libertad y de verdad. Tantos las relaciones entre naciones como la estructura interna de cada nación dependerán, bajo este paradigma, del grado de desarrollo de las fuerzas productivas y de la división del trabajo ${ }^{13}$.

El eurocentrismo hace referencia a cierta tendencia a considerar a Europa como centro o protagonista de la historia y la civilización humanas. El eurocentramiento de la economía - mundo asocia el ciclo de la modernidad a la expansión y la colonización del mundo por parte de las potencias europeas, al movimiento "civilizatorio" que traslada el eje desde Asia hacia Europa y legitima el tráfico de esclavos, el saqueo y la transferencia de recursos y el proceso de acumulación "originaria" del capital. El patrón moderno de poder y dominación funde la matriz eurocéntrica con las relaciones capitalistas. Como señala Quijano, "no hay modernidad sin colonialidad", es decir, sin destrucción de modos de producción previos, la bancarrota de los artesanos y la reconfiguración de la estructura social. La colonialidad eurocentrada impone una hegemonía mundial que se cristaliza en la

\footnotetext{
${ }^{10}$ Recordemos que la "Base Económica" es para Marx aquello que define al modo de producción, es decir, la interrelación dialéctica entre el desarrollo de las fuerzas productivas y las relaciones sociales de producción en el proceso productivo. El modo de producción hace referencia a un conjunto concreto, que ocurre históricamente, de relaciones sociales mediante las cuales se despliega trabajo para exprimir energía de la naturaleza por medio de utensilios, destrezas, organización y conocimiento (Wolf, 2005: 100)

${ }^{11}$ Para Lenin las contradicciones en la esfera de la producción (la base económica) no llevan necesariamente a la revolución ya que los obreros luchan por sus salarios, no contra la explotación y la falta de control del proceso de producción. El "Largo Siglo XX", en línea con la afirmación de Lenin, nos ha enseñado la paradoja de que allí donde había una organización proletaria y el desarrollo de las fuerzas productivas era mayor no ha habido grandes revoluciones (Wallerstein, 2002).

${ }^{12}$ Las fuerzas productivas expresan las interrelaciones entre los hombres, los instrumentos y la naturaleza con el fin de producir para alimentarse y elevar sus condiciones de vida. Por eso, las fuerzas productivas no son solamente las herramientas y las máquinas sino la manera en que se articulan todos sus componentes con las relaciones de producción en un trabajo concreto. Han sido formadas con los elementos de la naturaleza, como las materias primas, la tierra, la flora, la fauna, los suelos y el clima, que determinan en parte la producción (Vitale, 1992)

${ }^{13}$ En "La Ideología Alemana", Marx y Engels (1846) aceptan que estadios diferentes en la división social del trabajo corresponden a diferentes formas de propiedad. En este texto, el grado de avance de la conciencia (ideas, pensamiento, producción espiritual) depende del grado de desarrollo de las fuerzas productivas, y tanto las relaciones entre naciones como la estructura interna de cada nación dependen del grado de desarrollo de las fuerzas productivas y de la división del trabajo (industrial, comercial, agrícola; ciudad y campo). Es aquí donde se afirma que "al producir sus medios de vida, el hombre produce indirectamente su vida material", por lo tanto lo que los individuos son "depende de las condiciones materiales de su producción"
} 
universalización de las instituciones de los “ámbitos de existencia social” como el EstadoNación, la familia, la empresa y la racionalidad productivista (Quijano, 2000).

La misma categoría "pre-capitalista" que muchas veces utilizaron Marx y Engels (que luego veremos cómo es problematizada con la aparición de los formen), es una categoría eurocéntrica ya que supone como secuencias históricas previas a la mercantilización de la fuerza de trabajo a las relaciones de reciprocidad, esclavitud, servidumbre y producción mercantil independiente, cuando en realidad coexistieron y se combinaron de manera tal de retroalimentarse funcionalmente. En este sentido, como señala Lander, "El marxismo, la crítica más radical a la sociedad capitalista, no escapa del eurocentrismo y colonialismo característicos de los saberes modernos hegemónicos" (Lander, 2006).

La tradición "crítica" del difusionismo entenderá que el desarrollo del capitalismo a escala mundial estuvo y está muy lejos de ser una totalidad homogénea y continua. Por lo contrario, sostendrá que el patrón de poder mundial capitalista es una suma de elementos heterogéneos en lo que respecta a las formas del control del trabajo, los recursos y los productos.

\title{
Buscando el embrión difusionista en la obra de Marx y Engels
}

\author{
De lo que se trata es de saber si la humanidad puede cumplir su misión \\ sin una revolución a fondo en el estado social de Asia. Si no puede, \\ entonces, y a pesar de todos sus crímenes, Inglaterra fue el instrumento \\ inconsciente de la historia al realizar dicha revolución
}

Karl Marx

Entre los autores que podemos encuadrar bajo la tradición "difusionista", De Paula (2014) cita a Avineri (1968), Warren (1980), Kiernan (1974), Bernstein (1979), Mandle (1980), Brenner (1977), Palma (1978), Vujacic (1988) y Brewer (1990). Sin embargo, encontraremos que fue durante la III Internacional (komintern) bajo liderazgo de Stalin que esta visión se convertiría en hegemónica ya que se utilizó el DIAMAT como un modo de legitimar la estrategia política del Partido Comunista de la Unión Soviética (PCUS).

La dialéctica materialista (DIAMAT) fue, en palabras de Lefebvre (1979), "una tentativa de totalización, un sistema filosófico político, o sea, un neo-hegelianismo, una filosofía de Estado y una filosofía del Estado, supuesto resultado final de la filosofía de la historia y de la historia de la filosofía". En otras palabras, la DIAMAT constituyó una filosofía absoluta cuyo propósito era unificar distintas filosofías, distintas lecturas de Marx y distintas experiencias históricas en un gran relato que sirviera para legitimar el orden de las cosas existente en la Unión de las Repúblicas Socialistas Soviéticas de Stalin. Todas las experiencias históricas debían converger en el Estado stalinista, la realización de la razón absoluta. ¿Pero cómo llegó el pensamiento de Marx a convertirse en difusionista, y el difusionismo en la Ortodoxia del DIAMAT? 
Los "difusionistas" basan su análisis principalmente en los artículos de Marx sobre la India escritos en $1853^{14}$, aunque también encontrarían elementos en el "Manifiesto Comunista" (1848) y en el "Prólogo a la Contribución a la Crítica de la Economía Política" $(1859)^{15}$. Al contrario de estos escritos, la tradición crítica del difusionismo se basará en los estudios orientalistas de Marx.

En "Futuros resultados de la dominación británica en la India" (1853), Marx condena enfáticamente la empresa colonialista por su violencia e injusticia pero la vislumbra como progresista en el sentido histórico de la expansión de las relaciones capitalistas. En esta misma carta, caracteriza a Inglaterra como el "instrumento inconsciente de la historia" porque introduce las fuerzas de producción capitalistas y produce una revolución social, lo que hace que la potencia británica cumpla una función histórica progresista en la medida en que el "período burgués de la historia está llamado a crear las bases materiales de un nuevo mundo". En todas estas afirmaciones que realiza Marx asimila el progreso y la modernización al desarrollo de las fuerzas productivas, entendiendo este proceso como parte de un camino unilineal y universal hacia el socialismo. Marx caracteriza a la India como un "pueblo sin historia" y por lo tanto plantea una dicotomía en términos de qué sería preferible en términos históricos: "No se trata, por tanto, de si Inglaterra tenía o no tenía derecho a conquistar la India, sino de si preferimos una India conquistada por los turcos, los persas o los rusos a una India conquistada por los británicos" (Marx, 1853).

Así, tomando partido por la invasión inglesa, Marx afirma que Inglaterra tiene que cumplir en la India una doble misión: destructora por un lado y regeneradora por otro. Tiene que destruir la vieja sociedad asiática y sentar las bases materiales de la sociedad occidental en Asia.

Para ello, Marx debe apoyarse en una jerarquización de sociedades según el patrón civilización/barbarie, modernidad/atraso, afirmando que la ley histórica universal es la de la conquista de las naciones bárbaras por naciones civilizadas superiores. Bajo esta óptica, de acuerdo con una ley inmutable de la historia, los conquistadores bárbaros serían conquistados a su vez por la civilización superior ${ }^{16}$ (los pueblos "con historia"):

\footnotetext{
${ }^{14}$ Los artículos sobre la India se titulan "La dominación Británica en la India", "La compañía de las Indias Orientales" y "Resultados futuros de la dominación Británica en la India". Estos artículos fueron publicados entre Julio y Agosto de 1853 en el periódico New York Tribune.

${ }^{15}$ Por las características de este trabajo no se podrán analizar todos estos textos en profundidad aunque sí se incorporarán algunas referencias y notas al pie. En este apartado nos concentraremos en el texto "Futuros resultados de la dominación británica en la India" (1853).

${ }^{16}$ Esta idea se vincula con el concepto de "pueblos sin historia" elaborado por Engels. Para él, estos pueblos serían aquellos que carecen vitalidad para desenvolverse como pueblos independientes debido a factores históricos, geográficos, políticos e industriales. Esta caracterización fue quizás uno de los pecados más graves que cometió Marx en sus primeros escritos. Le valió críticas muy fuertes desde distintas disciplinas, ya que expresa cierto desprecio por la periferia, siendo uno de los aspectos más explícitamente eurocéntricos de su cosmovisión. Se recomienda la lectura del texto de Eric Wolf "Europa y la gente sin historia", Fondo de Cultura Económica, México, 1982.
} 
Los ingleses fueron los primeros conquistadores de civilización superior a la hindú, y por eso resultaron inmunes a la acción de esta última. Los británicos destruyeron la civilización hindú al deshacer las comunidades nativas, al arruinar por completo la industria indígena y al nivelar todo lo grande y elevado de la sociedad nativa. Las páginas de la historia de la dominación inglesa en la India apenas ofrecen algo más que destrucciones. Tras los montones de ruinas a duras penas puede distinguirse su obra regeneradora. Y sin embargo, esa obra ha comenzado (Marx, 1853).

La dominación británica en la India permitirá, desde la perspectiva de Marx, el desarrollo de las fuerzas productivas mediante la consolidación de la unidad política, el fortalecimiento del ejército, la introducción de la prensa libre, la expansión de las innovaciones tecnológicas y la educación y ciencia europea, la expansión del comercio (barcos, ferrocarriles, puestos) y la introducción de formas distintas de propiedad privada de la tierra (Zamindares y Ryotwares).

Ya han pasado más de 150 años desde la publicación de estas cartas. La India ha logrado su independencia aunque sin embargo todavía está lejos de convertirse en ese "espejo de su propio porvenir" en el que se veía reflejada en 1853 cuando miraba a Gran Bretaña.

\section{La canonización del marxismo en los manuales de economía y filosofía de la DIAMAT}

Únicamente la cosmovisión asentada en el profundo conocimiento de la teoría marxista leninista puede ayudar al hombre a orientarse justamente en el mundo en constante mutación. V. I. Lenin señaló que siguiendo el camino de la teoría marxista, iremos aproximándonos cada vez más a la verdad objetiva, pero siguiendo cualquier otro camino no llegaremos a ninguna parte excepto al embrollo y la mentira

Vladislav Krapivin

La tendencia "difusionista" compara a la historia con un proceso natural, de características objetivas, sometido a leyes de hierro, independientes de la voluntad, la conciencia y la actividad social de los seres humanos ${ }^{17}$. Este enfoque, según Kohan (2003), presenta con el Materialismo Dialéctico (DIAMAT) una visión de la historia con una dirección preestablecida. Desde esta cosmovisión filosófica universal se le imprime a la historia un carácter teleológico. El progreso histórico es interpretado "científicamente" como una sucesión de modos de producción en un sentido "progresivo" hacia el comunismo

\footnotetext{
${ }^{17}$ Esta lectura tiene consecuencias políticas cuando se postula en el caso de una intervención imperialista el "derecho a la civilización" de los pueblos "atrasados" o "sin historia" (más propia de una visión evolucionista y eurocéntrica de la historia que de una filosofía dialéctica). Según Kohan (2003), el "difusionismo" ha llevado a sectores de la izquierda en numerosas oportunidades a justificar intervenciones imperialistas y destrucción de formas no occidentales ni capitalistas de producción, cultura, organización, etc. En el Siglo XXI también lo sigue haciendo.
} 
proletario $^{18}$, lo que inevitablemente lleva a postulaciones dicotómicas del estilo civilización/barbarie para caracterizar las complejidades del tránsito de lo "atrasado" a lo "moderno": "La teoría evolucionista confirmó la idea principal de la dialéctica: la idea del desarrollo, de la transición de lo simple a lo complejo, de lo inferior a lo superior" (Krapivin, 1985: 90)

La filosofía de la historia del marxismo difusionista encuentra el motor de la historia en el desarrollo de la productividad del trabajo y el progreso técnico: lo que en una lectura reduccionista de Hegel sería el "autodespliegue del espíritu" en Marx sería el desarrollo de las fuerzas productivas y materiales (Tarcus, 2008). Bajo esta perspectiva, el movimiento de la historia se reduce al desarrollo de las tareas pendientes de la revolución democráticoburguesa. En el contexto en el que fueron enunciadas, estas tareas fueron entendidas como el desarrollo de las fuerzas productivas, para que se pudieran dar las condiciones "objetivas" de la construcción del comunismo".

Para Kohan (2003), la tradición teórico-filosófica del DIAMAT ha tenido fuertes implicancias, que se deben no tanto a las formulaciones originales (del puño de Marx y Engels) como al posterior desarrollo en manos del movimiento obrero y de la construcción del socialismo en la URSS. La relevancia del estudio del materialismo dialéctico que aquí se presenta radica precisamente en que el DIAMAT ha sido la interpretación hegemónica de la filosofía marxista en el Siglo XX.

En particular, habrían sido los aportes de Kautsky y Plejanov ${ }^{20}$ quienes, junto a Stalin y Bujarin ${ }^{21}$, le darían su forma definitiva en la III Internacional Comunista, lo que se conocería años más tarde como la "ortodoxia" comunista a escala mundial, cristalizada en los manuales de economía y filosofía de la URSS.

Kohan (2003) estudia y reseña las estructuras argumentativas de los manuales de Kuusinen (1961), Kelle y Kovalson (1962), Makarov (1965), Afanasiev (1973), Gleserman y Kursanov (1975), Shajnazarov (1981) y Vlasova (1987). En todos ellos encuentra las mismas secuencias y fundamentos filosóficos, orientados a justificar la visión oficial del

\footnotetext{
${ }^{18}$ En un ensayo de 1905, Stalin desarrolla la idea de que la ciencia social se deriva de la ontología natural, y que el socialismo proletario es la derivación política "natural" del sistema filosófico del materialismo dialéctico (Stalin, 1938)

${ }^{19}$ En su conocido pasaje del "Prólogo a la Contribución a la Crítica de la Economía Política" (1859), Marx afirma que la conciencia debe explicarse por las contradicciones de la vida material, es decir, las que se generan una vez que el desarrollo de las fuerzas productivas entre en conflicto con las relaciones sociales de producción existentes: "Y del mismo modo que no podemos juzgar a un individuo por lo que él piensa de sí, no podemos juzgar tampoco a estas épocas de transformación por su conciencia, sino que , por el contrario, hay que explicarse esta conciencia por las contradicciones de la vida material, por el conflicto existente entre las fuerzas productivas sociales y las relaciones de producción. Ninguna formación social desaparece antes de que se desarrollen todas las fuerzas productivas que caben dentro de ella, y jamás aparecen nuevas y más elevadas relaciones de producción antes de que las condiciones materiales para su existencia hayan madurado dentro de la propia sociedad antigua" (Marx, 2001).

${ }^{20}$ Plejanov fue quien, según Kohan, dedujo "la imposibilidad de forzar, negar o violar 'las férreas leyes de la historia' y, por lo tanto, de cualquier tipo de transformación socialista en su país que no pasase previamente por la etapa y los estadios del desarrollo capitalista occidental europeo" (Kohan, 2003: 39)

${ }^{21}$ Es Bujarin quien plantea en el VI Congreso de la Internacional Comunista (1928) que el DIAMAT es tanto el método como la concepción del mundo sobre la que se levanta la Internacional.
} 
DIAMAT: se presenta el problema de la filosofía ${ }^{22}$, se definen la Materia y la Conciencia ${ }^{23}$, se caracteriza a la dialéctica como la ciencia general del desarrollo y se describen sus leyes $^{24}$, se expone la teoría estalinista del retardo de la conciencia, se presenta una crítica a las filosofías burguesas contemporáneas, y se describe el materialismo histórico y la teoría de la revolución y el progreso (Kohan, 2003).

La teoría del retardo de la conciencia merece un párrafo aparte ya que presenta un perfecto ejemplo de determinismo, reducción economicista y de interpretación productivista. En ella, Stalin afirma que los "cambios en el mundo exterior" preceden necesariamente a los "cambios en la conciencia", que es concebida como "epifenómeno" del avance de las fuerzas productivas en general, y en particular de los instrumentos de producción (herramientas y tecnologías) ${ }^{25}$.

En el "Manual de Marxismo-Leninismo" editado por Kuusinen en 1960 podemos hallar un claro ejemplo del modo en que el DIAMAT convirtió a la filosofía de la historia marxista en un dogma oficial:

(...) la totalidad de los pueblos recorren en líneas generales un mismo camino. La historia de cada uno de ellos, en resumidas cuentas, viene condicionada por el desarrollo de las fuerzas productivas, que se subordina a unas mismas leyes internas. La sociedad avanza mediante una sucesión consecutiva y sujeta a leyes de las formaciones económico-sociales; y el pueblo, que vive dentro de una formación más avanzada muestra al resto su futuro de la misma manera que fuera de él ve su pasado (Kuusinen, 1961 - citado en De Paula, 2014: 153).

Una concepción similar podemos encontrar en el manual de la editorial Progreso de Moscú, “QQué es el materialismo dialéctico?” de Krapivin (1985), perteneciente a la colección $\mathrm{ABC}$ de conocimientos socio-políticos:

La filosofía marxista-leninista constituye el fundamento teórico general de la cosmovisión científica. Pertrecha a los hombres con el conocimiento de las leyes de la naturaleza, de la sociedad y el pensamiento. El conocimiento de esas leyes es imprescindible para la transformación revolucionaria práctica del mundo. De tal suerte, la filosofía marxista-leninista es la ciencia que revela las leyes más generales dialécticas del mundo material, las vías de su conocimiento y transformación revolucionarias (Krapivin, 1985: 24)

\footnotetext{
${ }^{22}$ Para Engels, la filosofía "materialista" radica en el estudio de la relación del ser humano con la naturaleza objetiva-material, que se piensa a través de la categoría "fuerzas productivas" (Kohan, 2003).

23 En estos manuales, la materia tiene una realidad objetiva al margen del hombre y la conciencia es un producto del cerebro y se define como materia altamente organizada

${ }^{24}$ Para Engels, la dialéctica consistía en la unidad y lucha de contrarios, cambios de cantidad en calidad y negación de la negación, y sus correspondientes categorías dialécticas: singular, particular, universal, causa y efecto, necesidad y casualidad, posibilidad y realidad, esencia y fenómeno, etc. (Kohan, 2003).

25 Las fuerzas productivas están constituidas por los instrumentos de trabajo (herramientas, utensilios, máquinas, etc.) o los medios de producción pero también por la fuerza de trabajo de los hombres que los fabrican y los ponen en movimiento. El reduccionismo productivista de la ortodoxia del DIAMAT centró únicamente el desarrollo de las fuerzas productivas en las máquinas e instrumentos de trabajo.
} 
La conversión del pensamiento marxista en la doctrina oficial del comunismo soviético provocó la esterilización de su esencia crítica, convirtiéndolo en un dogma que sirvió como "medio de legitimación basado en la repetición mecánica de citas, justificación y obediencia teórica" (Kohan, 2003: 53):

La aparición y el desarrollo de la filosofía marxista-leninista es consecuencia del desarrollo del pensamiento científico, del desarrollo de la sociedad en general (...) no fue un fenómeno casual. Es resultado del progreso de la humanidad (...) pudo ser elaborada solo como consecuencia del duradero proceso de desarrollo de la sociedad humana, de la filosofía, de las ciencias naturales y sociales (Krapivin, 1985: 84)

\section{El "otro" Marx: la tradición crítica del difusionismo a través de las cartas sobre la cuestión Rusa}

Sucesos notablemente análogos pero que tienen lugar en medios históricos diferentes conducen a resultados totalmente distintos. Estudiando por separado cada una de estas formas de evolución y comparándolas luego, se puede encontrar fácilmente la clave de este fenómeno, pero nunca se llegará a ello mediante el pasaporte universal de una teoría histórico-filosófica general cuya suprema virtud consiste en ser suprahistórica

El descubrimiento de los textos conocidos como los Grundisse (en particular aquellos incluidos en los "Formen" -Formaciones Económicas Precapitalistas-) en la década del '50, junto con el intercambio postal con los/as populistas rusos/as, nos permite vislumbrar cómo el propio Marx repensó sus propias categorías y problematizó las transiciones, a través de la incorporación del modo asiático y otras derivaciones del modo comunal como el sistema germánico y el eslavo, agregando componentes de complejidad y multilinealidad.

La incorporación de estos textos nos permite vislumbrar la posibilidad de una "segunda tendencia" en el pensamiento de Marx y en el marxismo posterior, muy diferente a la canonizada por la ortodoxia comunista en la tradición difusionista. El último Marx cuestiona desde el punto de vista ético, moral, histórico y económico la supuesta misión civilizatoria del imperialismo. La destrucción de las propiedades comunales de la tierra será vista ahora como una destrucción de fuerzas productivas.

Generalmente, quienes encuentran un Marx con una filosofía de la historia multilineal (es decir, ni teleológica, ni evolucionista, ni determinista, ni eurocéntrica ni economicista) suelen recuperar las cartas sobre Rusia ${ }^{26}$, los trabajos sobre Irlanda ${ }^{27}$, Polonia $^{28}$, España y China y los formen incluidos en los Grundisse.

\footnotetext{
${ }^{26}$ Las cartas sobre Rusia incluyen el "Proyecto de Respuesta a la carta a V. I. Zasulich" (1881), la "Carta a Vera Zasulich" (1885), y la "Carta al director de Otiechéstvennie Zapiski" (1887)

${ }^{27}$ En el abordaje de la cuestión Irlandesa está la clave de la interpretación de los dos paradigmas sobre la cuestión de Centro y Periferia. Por un lado, desde la economía se planteará la tendencia a la polarización y fractura, que genera polos de desarrollo y subdesarrollo. Por el otro lado, desde la política, se planteará la
} 
A partir de estos textos, el atraso se muestra más como una oportunidad que como un obstáculo y, como señala Tarcus, "La Filosofía de la Historia parece disolverse, finalmente, en la teoría de la historia. La técnica deviene política" (Tarcus, 2008). Este Marx desarrolla una lectura dialéctica del progreso, donde la historia prosigue a través de saltos y contradicciones y nunca como una escalera de etapas sucesivas. Así, existe también un Marx cuyo método consiste en "estudiar en su especificidad los diferentes medios históricos para luego compararlos entre sí y no en la aplicación de la "clave universal de una teoría general de filosofía de la historia, cuya mayor ventaja reside precisamente en el hecho de ser una teoría suprahistórica" (Tarcus, 2008).

En el Proyecto de Respuesta a la carta a V. I. Zasulich (1881) y la Carta a Vera Zasulich (1885) ${ }^{29}$ Marx se propone estudiar la comuna rural rusa evaluando su factibilidad como base de un desarrollo específico de socialismo y llega a cuestionar su propia filosofía de la historia, comprendiendo la que el eje insurreccional había pasado desde la Europa occidental a la oriental, lo que daría lugar más adelante a la famosa tesis leninista que afirmaba que "la cadena se rompe por el eslabón más débil".

En la carta mencionada, Marx admite que la "fatalidad histórica" del movimiento de la expropiación de los campesinos (la llamada "acumulación originaria") está restringida únicamente a los países de Europa Occidental. Por estos motivos, Marx evalúa las posibilidades objetivas y subjetivas de utilizar la comuna agrícola rusa como embrión de un nuevo modo de producción colectivista. Para Marx, la propiedad común es "fuente de una vida vigorosa y firme" mientras que "la casa y el cultivo parcelario y apropiación privada admite un desarrollo de la individual incompatible con las condiciones de las comunidades más primitivas" (Marx, 1881). Más allá de esta potencialidad, Marx señala que para lograr mantener la comunidad rural que existe a escala nacional se debe desarrollar directamente como elemento de la producción colectiva a escala nacional y no como elementos disociados del sistema con relativo aislamiento. De este modo, al ser contemporánea a la producción capitalista, la agricultura comunal podría aprovecharse de sus avances, consiguiendo equipos, fertilizantes, métodos agronómicos y medios imprescindibles para el trabajo colectivo.

En su Carta al director de "Otiechéstvennie Zapiski" (1877) Marx admite que si Rusia sigue los pasos de Europa Occidental en su transformación hacia el capitalismo deberá transitar la misma acumulación originaria, transformando los campesinos en proletarios, lo que la hará experimentar las propias leyes "despiadadas" del capitalismo, pero que este no es un paso necesario ni irrevocable. En última instancia, la supervivencia de este actor social y de esa forma de propiedad dependerá de la lucha de clases. En este

multilinealidad de los caminos que conducen a la consolidación del moderno estado nación, lo que llevará a una estrategia política antiimperialista (Katz, 2016)

${ }^{28}$ Sobre Polonia sostiene en 1875: "En la medida en que un pueblo vital es aplastado por un conquistador externo, utiliza obligatoriamente todas sus fuerzas, todos sus esfuerzos, toda su energía contra el enemigo exterior; su vida interna queda paralizada y se vuelve incapaz de luchar por su emancipación social" (Citado en Kohan, 2003: 244)

29 Vera Zasulich era partidaria de los populistas rusos (los narodniki) y postulaba la inquietud de pasar del feudalismo al socialismo sin la necesidad de pasar por "las horcas caudinas de la acumulación primitiva del capital, con toda su secuela de violencia, miseria y crisis social” para ingresar en la civilización moderna. 
texto Marx cierra su interpretación afirmando que "Sucesos notablemente análogos pero que tienen lugar en medios históricos diferentes conducen a resultados totalmente distintos. Estudiando por separado cada una de estas formas de evolución y comparándolas luego, se puede encontrar fácilmente la clave de este fenómeno, pero nunca se llegará a ello mediante el pasaporte universal de una teoría histórico-filosófica general cuya suprema virtud consiste en ser suprahistórica" (Marx, 1877)

La correspondencia de Marx con los populistas rusos y, principalmente, el borrador de la carta a Vera Zazulich, nos permiten evaluar cuánto influyó su valoración de la comuna rural rusa en un embrión de una nueva filosofía de la historia, donde el problema nacional-colonial y la multiplicidad de vías de "desarrollo" tendrían un peso mayor. El estudio de la llamada 'cuestión rusa' sería uno de los aspectos que permitiría a Marx desligarse de las versiones más productivistas, progresistas y eurocéntricas de su filosofía de la historia e incorporar un marco analítico dialéctico donde la historia no avanzaba sino a través del desarrollo de la contradicción y la lucha de clases.

\section{Lecturas críticas de la tradición difusionista}

Los colgantes que Zhenia llevaba al cuello, su largo y firme cuello, eran claro síntoma de los tiempos: al lado de una medalla con la sempiterna hoz y el martillo, acaso subastada por un héroe de la URSS, lucía un símbolo hippie de la paz, una medalla de San Jorge con dragón incluido y una calavera que un par de años atrás habría sido imposible de ver en Moscú. Cuando a Oksana se le ocurrió preguntar por el significado de aquellos dijes, Zhenia le respondió que solo le gustaban las figuritas

Jorge Volpi, No será La tierra

Kiernan (1974), Aricó (2010), Kohan (2003) y Bianchi (2010) iluminan la relación que existe entre el DIAMAT, el difusionismo y la filosofía hegeliana de la historia. Desde su perspectiva, los difusionistas no logran romper con el carácter teleológico de la filosofía de la historia hegeliana, en el que la humanidad, independientemente de las acciones que emprenda, realiza un fin (la razón absoluta) escrito de antemano, que estaría en cierto sentido predeterminado. En el plano de los modos de producción, el sentido de la historia contaría con cinco etapas universales que se sucederían linealmente: sociedad primitiva, esclavismo, feudalismo, capitalismo, socialismo (comunismo).

Marx desarrolló sus estudios del Modo de Producción Asiático (MPA) en el texto "Formaciones Económicas Pre-Capitalistas", que formó parte de los Grundrisse (un borrador de El Capital escrito en 1858). En un artículo denominado "Difusión y recepción de los Grundrisse en el mundo", Marcello Musto (2010) afirma que luego de la muerte de Marx, Engels no los habría leído y por lo tanto no los habría incorporado en la edición definitiva de El Capital. Por una serie de avatares, los formen no serían descubiertos sino hasta 1923 por David Riazanov, director del Instituto Marx-Engels (MEI) de Moscú. 
La edición completa de los Grundrisse que contiene los formen se publicaría recién en 1953 en Alemania Oriental ${ }^{30}$ (la edición en Inglés realizada por Hobsbawm -que se haría mundialmente conocida- sería recién diez años más tarde), casi un siglo después de haber sido escritos. En los formen Marx analiza la formación social de la India y elabora el concepto de "Modo de Producción Asiático" (MPA) ${ }^{31}$, que se volvió relevante años más tarde cuando vio la luz ya que presentaba un "estadio" del desarrollo histórico por el cual no habían pasado los países de Europa Occidental y que por lo tanto no había sido considerado en la teorización realizada por aquellas lecturas más deterministas, eurocéntricas y evolutivas de la Obra de Marx.

La aparición del MPA permitiría recuperar desde los propios escritos de Marx una conceptualización multilineal del desarrollo histórico ${ }^{32}$ que aportaría argumentos contra la ortodoxia comunista canonizada en el DIAMAT. No por casualidad, la edición completa de los Grundisse sería excluida de la publicación soviética de 1956-1968 de las Obras Completas de Marx \& Engels (conocidas mundialmente como MEW -Marx Engels Werke $)^{33}$, que fue "la edición más ampliamente usada de las obras de Marx y de Engels, así como la fuente de la traducción a la mayoría de los demás idiomas” (Musto, 2010:4).

Tanto la correspondencia entre Marx y Vera Zasulich como los Formen serían publicados recién en la segunda mitad del Siglo XX. Con la aparición de los Formen, el esquema presentado en la Ideología Alemana (comunismo primitivo - antigüedad - feudalismo capitalismo -comunismo) se alteraría notablemente, ya que con el descubrimiento del "Modo de producción asiático" (que no era una sociedad de clases) Marx vislumbró que a partir del Sistema Comunal Primitivo había por lo menos tres o cuatro caminos alternativos de "desarrollo": comunidades primitivas, sistema oriental, sistema eslavo (propiedad comunal directa); sistema antiguo, sistema germánico (propiedad comunal con un sistema de clase).

Así, en los Formen es evidente que Marx no se refiere a una sucesión cronológica ni a la evolución de un sistema a partir de su predecesor (salvo el caso del feudalismo y el capitalismo) sino a un tránsito un sentido más general y menos determinístico. La

\footnotetext{
${ }^{30}$ Paradójicamente, sería en el momento más alto de la ortodoxia comunista del DIAMAT (y en el año de la muerte de Stalin) cuando este texto, que con el correr de los años aportaría elementos para erosionar sus bases, vería la luz.

${ }^{31}$ Las principales características del MPA consistían en utilizar grandes obras de irrigación (que requerían un Estado con más peso que en las Formaciones Occidentales), en poseer una propiedad comunal de la tierra (no había separación de los productores y los medios de producción), la unidad entre la manufactura y la agricultura en el entorno rural (lo que hacía más eficiente a la producción y dotaba a las aldeas de autarquía e imponía un obstáculo a la penetración del comercio) (De Paula, 2014).

32 Como advierte De Paula (2014) la negación de la unilinealidad no debe devenir en un relativismo de considerar multilineal a un proceso carente de condicionamientos, sino que deben considerarse las limitaciones materiales de cada momento histórico y las leyes internas de los modos de producción y los niveles diferentes de las formaciones sociales para avanzar en un análisis científico. Leon Trotsky, Rosa Luxemburgo, Gyorgy Lukakcs, Antonio Gramsci, Herbert Marcuse, Karl Korsch y Walter Benjamin, entre muchos otros, constituyen ejemplos de la aplicación marxista de una filosofía de la historia multilineal

33 Los Grundisse (escritos entre 1857 y 1858) también aportarían elementos de crítica a las lecturas althusserianas que identifican en la obra de Marx un "Marx joven" y un "Marx maduro" con un criterio estrictamente cronológico.
} 
"evolución" de estos sistemas no se lee en términos de progreso sino de apartamiento paulatino a la situación originaria del hombre ${ }^{34}$.

Según Tarcus (2008), el "otro" Marx superaría su perspectiva progresistaevolucionista y se metería de lleno en el análisis del desarrollo desigual del capitalismo girando hacia una filosofía de la historia abierta y en función de la lucha de clases. A partir de estos textos, el atraso puede mostrarse más que como un obstáculo como una oportunidad y el progreso pasa a ser un valor social, "un debate público y decisión colectiva sobre los fines, las vías y los costos del progreso".

\section{Reflexiones Finales y derivas contemporáneas del debate}

\section{El concepto de progreso debe ser fundamentado en la idea de catástrofe. Que las} cosas continúen así es la catástrofe

Walter Benjamin

¿Por qué estudiar hoy la crisis del marxismo y las diferentes filosofías de la historia? Con el fin de la guerra fría y la decadencia de las experiencias del socialismo real, el sistema mundial ha perdido el contrapeso que generaba la existencia de un "polo" alternativo al capitalismo. La desaparición del polo alternativo no solo empeoró la correlación de fuerzas a para los sectores populares y trabajadores de todo el mundo, sino que además hizo que el horizonte emancipatorio compartido se diluyera y se fragmentara en luchas atomizadas.

Con la crisis del marxismo y la caída del campo socialista se ha impuesto a nivel mundial la idea del "fin de la historia" enunciada por Francis Fukuyama, funcional a la implementación del Consenso de Washington y la profundización del neoliberalismo. La forma que adopta la fase actual del desarrollo del capitalismo se construyó sobre el desmantelamiento del Estado de Bienestar, una violenta campaña contra las estructuras tradicionales de la fuerza de trabajo, un redoblado disciplinamiento del trabajo, el desconocimiento de las estructuras colectivas de trabajadores como interlocutores válidos ante el Estado, la modificación de las formas de organización del trabajo en la producción, circulación y distribución de mercancías, la innovación tecnológica, la refuncionalización de técnicas, estructuras laborales, formaciones comunitarias, saberes y esfuerzos laborales no capitalistas hacia la acumulación capitalista, una nueva división mundial del trabajo y la

\footnotetext{
34 Con la aparición de los Grundisse y los posteriores estudios del Siglo XX sobre el desarrollo y subdesarrollo se pondrían sobre el foco la cuestión del desarrollo desigual y combinado producto del propio proceso de expansión capitalista. El concepto de "desarrollo desigual y combinado" de Trotsky presenta el punto de ruptura con la cosmovisión del DIAMAT y la comprensión de la filosofía universal de la historia prevaleciente en la ortodoxia comunista de la III Internacional. Esta "ley" afirma que en el desarrollo social de distintas cultura existen distintas etapas y distintas fases, que se pueden presentar de forma combinada, donde unas no superan a las otras en términos de progreso. Estas ideas ya se encontraban presentes en las “Tesis de Abril" escritas por Lenin en 1917. En estos escritos del "segundo Lenin", polemiza con las lecturas evolucionistas y eurocéntricas de la ortodoxia de la II Internacional (de Kautsky, Plejanov y la "ortodoxia”) y "descubre" la cuestión colonial y la cuestión nacional, dando origen a la III Internacional Comunista (en un período previo a su estalinización).
} 
búsqueda de una nueva composición orgánica del capital a escala planetaria e histórica (García Linera, 2009).

La expansión del capitalismo a escala mundial ha llegado a ser prácticamente absoluta. La fase contemporánea de la globalización permite profundizar las tendencias universalizantes de la acumulación del capital gracias a la formación de una red de transporte y comunicaciones funcional a la acumulación del capital y a la producción de mercancías con ánimo de lucro, lo que consolida el proceso de subsunción real de los medios de intercomunicación al capital. Asimismo, se consolida una base mundializada de la producción ya que tanto las materias primas, la tecnología y los mercados como la propia producción del bien final se encuentran descentralizadas, lo que provoca que el espacio mundial se nos aparezca como un "espacio geográfico unificado donde se despliega la actividad completa de elaboración de cualquier mercancía” (García Linera, 2009: 85).

El desarrollo de las fuerzas productivas en el marco del sistema capitalista, lejos de algunas proyecciones catastrofistas y fatalistas de fines del Siglo XIX y comienzos del Siglo XX, ha llevado a una expansión inédita en los medios de comunicación, consumo y producción. El desarrollo de innovaciones en la producción de energía, materiales conductores, microbiología, computadoras, robots, tecnologías de la comunicación (fibra óptica, comunicación satelital, digitalización de operaciones, etc.) son solo muestras de ello.

Sin embargo, este desarrollo no es neutral ni tampoco se da de forma unilateral, ya que el capital no desarrolla cualquier fuerza productiva sino únicamente aquella que le permite conquistar su propósito de valorizar el valor. Las fuerzas productivas ya desarrolladas que se interponen en su camino pueden ser destruidas, mutiladas o reprimidas. El capital desarrolla solo aquellas fuerzas productivas que puedan volverse funcionales a su acumulación sin tener cuidado de su racionalidad eficiencia o sostenibilidad sino únicamente en la dimensión que le ofrece el valor. De este modo, la mundialización y el desarrollo de las fuerzas productivas se dan bajo una forma enajenada por el lucro privado y el interés capitalista, mutilando formas de desarrollo asociadas a dimensiones no vinculadas con la valorización del valor ${ }^{35}$, e incluso promoviendo desarrollos que destruyen el sustrato material sobre el que se sostiene la acumulación del capital. De esta mundialización y de este tipo de desarrollo de las fuerzas productivas, que son empujados bajo una forma enajenada por el lucro privado y el interés capitalista, como señala Linera, "no viene, ni puede venir, por 'desarrollo automático', o mero crecimiento lineal, la habilitación de una nueva forma social de producción” (García Linera, 2009: 95). Lejos de las lecturas unidimensionales de aquellos postulados productivistas y tecnologicistas que hemos reseñado en este trabajo, nos interesa recuperar el legado "dialéctico" y "humanista" de Marx y Engels, donde las fuerzas productivas son comprendidas como una relación social y por lo tanto también se encuentran atravesadas

\footnotetext{
35 "La interdependencia universal del trabajo, la creatividad, el intelecto social general, la ciencia, todas ellas capacidades sociales que han despertado al influjo de la sociedad moderna y que llevan en ciernes una infinidad de fuerzas capaces de fortalecer aptitudes humanas y de satisfacer requerimientos colectivos, son sistemáticamente extorsionadas para adecuarse a la estrecha disciplina de la ganancia" (García Linera, 2009: 94)
} 
por la lucha de clases y donde el imperialismo es condenado desde un punto de vista ético, moral, histórico y económico.

El "Largo Siglo XX" nos ha enseñado la paradoja de que allí donde había una organización proletaria y el desarrollo de las fuerzas productivas era mayor no han habido grandes revoluciones. No ha sido el proletariado industrial de los países "avanzados" de Europa Occidental quien se hizo cargo de su "rol histórico" como sujeto y eje de la revolución mundial. Las atrocidades cometidas en nombre del socialismo y del marxismo y la deriva de los "socialismos reales" llevaron a una crisis del marxismo sin precedentes y de una escala difícil de conmensurar. Sin embargo, la oportunidad de realizar un "balance crítico" de estas experiencias sigue teniendo vigencia a pesar de los 40 años que pasaron desde que Althusser pronunciara sus palabras.

La caracterización de las experiencias del socialismo real y las derivas posibles de la(s) filosofía(s) marxista(s), como se intentó mostrar en este trabajo, deberían permitirnos elaborar un balance crítico sin tener que "tirar al niño con el agua del baño", es decir, sin tener que desechar definitivamente al marxismo como una herramienta para permitirnos transformar las injusticias que la realidad nos impone.

\section{Bibliografía}

Althusser, L. (1977): "Seis iniciativas comunistas", Siglo XXI de España Editores, S. A., 1977. Althusser, L. (1978a), "Dos o tres palabras (brutales) sobre Marx y Lenin" (Traducido por Ana María de Rodríguez), Revista de la cultura de occidente Bogotá, tomo XXII/5, marzo 1978, № 197. Althusser, L. (1978b): "Lo que no puede durar en el Partido Comunista", Siglo XXI de España Editores, S. A., 1978.

Anderson, K. (2010): Marx at the margins, University Of Chicago Press, 2010.

Anderson, P. (1975): "Una entrevista político-filosófica con Lucio Colletti", Cuadernos Políticos, número 4, México D.F., editorial Era, julio-septiembre de 1975, p. 61-82.

Aricó, J.M. (2010): Marx y América Latina, Buenos Aires, Fondo de Cultura Económica, 2010.

Balibar, E. (2015): "El infinito adiós al marxismo". Revista MetaPolítica, September 9, 2015.

Bianchi, A. (2010). O marxismo fora do lugar. Política \& Sociedade. Volume 9. № 16 - abril de 2010.

De Paula, P. G. (2014): "Duas teses sobre Marx e o desenvolvimento: considerações sobre a noção de desenvolvimento em Marx". Dissertação de Mestrado do Programa de Pós-Graduação em Políticas Publica, Estratégias e Desenvolvimento (PPED). Instituto de Economia (IE), Universidade Federal do Rio de Janeiro (UFRJ). Rio de Janeiro: Fevereiro 2014.

García Linera, Á. (2009): La potencia plebeya: acción colectiva e identidades indígenas, obreras y populares en Bolivia / Álvaro García Linera; compilador Pablo Stefanoni. - Bogotá: Siglo del Hombre Editores y Clacso, 2009.

Hobsbawm, E. (2001): Historia del siglo XX, Barcelona, Crítica, 2001.

Katz, C. (2016): "Marx y la Periferia". Publicado en http://katz.lahaine.org/?p=269 el 28 de Marzo de 2016.

Kiernan, V.G. (1974). Marxism and Imperialism. Londres: Edward Arnold Publishers

Kohan, N. (2003): "Marx en su Tercer Mundo. Hacia un socialismo no colonizado". La Habana, Centro de Investigación y Desarrollo de la Cultura Cubana Juan Marinello, 2003. 
Krapivin, V.(1985): “QQué es el materialismo dialéctico?”. Colección ABC de conocimientos sociopolíticos, Editorial Progreso, Moscú, 1985.

Lander, E. (2006): "Marxismo, eurocentrismo y colonialismo" Buenos Aires: CLACSO, agosto 2006.

Lowy, M. y Traverso, E. (1990): The Marxist Approach to the National Question: A Critique of Nimni's Interpretation", Science \& Society, Vol. 54, No. 2 (Summer, 1990), pp. 132-146.

Marx, C. (1853): "Formas que preceden a la producción capitalista" en HOBSBAWM, E.: Karl Marx - Formaciones económicas precapitalistas", Buenos Aires, Cuadernos de Pasado y Presente ${ }^{\circ}$ 20, 1974.

Marx, C. (1853): "Futuros resultados de la dominación británica en la India", en Obras escogidas en tres tomos (Editorial Progreso, Moscú, 1974), t. I.

Marx, C. (1859): "Prólogo a la Contribución a la Crítica de la Economía Política", en Marxists Internet Archive, marzo de 2001.

Marx, C. (1867): El Capital. Madrid: Akal, 2000.

Marx, C. (1881): "Proyecto de Respuesta a la carta a V. I. Zasulich", en Obras escogidas en tres tomos (Editorial Progreso, Moscú, 1974), t. III.

Marx, C. (1885): "Carta a Vera Zasulich", en Obras escogidas en tres tomos (Editorial Progreso, Moscú, 1974), t. III.

Marx, C. (1887): "Carta al director de Otiechéstvennie Zapiski", en Obras escogidas en tres tomos (Editorial Progreso, Moscú, 1974), t. III.

Marx, C. y Engels, F. (1846): La ideología alemana. Trad. al castellano de W. Roces. Marxists Internet Archive, 2011-2012.

Musto, M. (2010): "Difusión y recepción de los Grundrisse en el mundo", Revista Herramienta No. 7, Diciembre de 2010.

Quijano, A. (2000): “Colonialidad del poder, eurocentrismo y América Latina”. En Edgardo Lander (comp.) "La colonialidad del saber: eurocentrismo y ciencias sociales. Perspectivas Latinoamericanas". CLACSO, Consejo Latinoamericano de Ciencias Sociales, Buenos Aires, Argentina. Julio de 2000.

Perez, D. (2007): "Las lecturas marxistas de Walter Benjamín en sus estudios sobre la experiencia de la temporalidad moderna", AdVersuS, Año IV,- No 8-9, abril-agosto 2007

Sánchez Vázquez, A. (1981): "Ideal Socialista y Socialismo Real”, Revista Nexos, 1981.

Stalin, J. (1938): "Sobre El materialismo dialectico Y el materialismo histórico", en Stalin, J, Cuestiones del leninismo, Pekín: Ediciones en lenguas extranjeras, Primera edición 1977, págs. 849-90.

Tarcus, H. (2008): “¿Es el marxismo una Filosofía de la Historia? Marx, la Teoría del Progreso y la "Cuestión Rusa"'. Buenos Aires, Andamios. Revista de Investigación Social, Junio, 7-32, 2008.

Vitale, L. (1992): "Modos de producción y formaciones sociales en América Latina". En. Introducción a una teoría de la historia para América Latina. Bs.As., Planeta, 1992

Wallerstein, I. (coord.) (2002): Conocer el mundo. Saber el mundo. El fin de lo aprendido. México D.F., Siglo Veintiuno Editores, 2002.

Warren, B. (1980): Imperialism, pioneer of capitalism, NLB/Verso, London.

Wolf, E. (1982): Europa y la gente sin historia, Fondo de Cultura Económica, México, 1982. 